\title{
Evolution and challenges of dynamic global vegetation models for some aspects of plant physiology and elevated atmospheric $\mathrm{CO}_{2}$
}

\author{
L. F. C. Rezende $^{1}$ - B. C. Arenque ${ }^{2}$ - S. T. Aidar ${ }^{3}$ - M. S. B. Moura ${ }^{3}$ - C. Von Randow ${ }^{1}$. \\ E. Tourigny ${ }^{1}$ - R. S. C. Menezes ${ }^{4}$ - J. P. H. B. Ometto ${ }^{1}$
}

Received: 18 July 2015 / Revised: 6 October 2015 / Accepted: 13 October 2015 / Published online: 23 October 2015

(C) ISB 2015

\begin{abstract}
Dynamic global vegetation models (DGVMs) simulate surface processes such as the transfer of energy, water, $\mathrm{CO}_{2}$, and momentum between the terrestrial surface and the atmosphere, biogeochemical cycles, carbon assimilation by vegetation, phenology, and land use change in scenarios of varying atmospheric $\mathrm{CO}_{2}$ concentrations. DGVMs increase the complexity and the Earth system representation when they are coupled with atmospheric global circulation models
\end{abstract}

\section{F. C. Rezende}

luiz.rezende@inpe.br

B. C. Arenque

barenque@usp.br

S. T. Aidar

saulo.aidar@embrapa.br

M. S. B. Moura

magna.moura@embrapa.br

C. Von Randow

celso.vonrandow@inpe.br

E. Tourigny

etiennetourigny@gmail.com

R. S. C. Menezes

rmenezes@ufpe.br

J. P. H. B. Ometto

jean.ometto@inpe.br

1 Earth System Science Center, National Institute for Space Research (INPE), Av. dos Astronautas, 1758 - Jd. da Granja, CEP:

12227-010 São José dos Campos, SP, Brazil

2 Botany Department, University of São Paulo (USP), R. do Matão, 277, CEP: 05508-090 Butantã, SP, Brazil

3 Embrapa Tropical Semiarid Brazilian Agricultural Research Corporation (EMBRAPA), Rodovia BR-428, Km 152, Zona Rural, CEP: 56302-970 Petrolina, PE, Brazil

4 Federal University of Pernambuco (UFPE), Av. Prof. Luis Freire, 1000, CEP: 50740-540 Cidade Universitária, Recife, PE, Brazil
(AGCMs) or climate models. However, plant physiological processes are still a major source of uncertainty in DGVMs. The maximum velocity of carboxylation $\left(\mathrm{Vc}_{\max }\right)$, for example, has a direct impact over productivity in the models. This parameter is often underestimated or imprecisely defined for the various plant functional types (PFTs) and ecosystems. $\mathrm{Vc}_{\max }$ is directly related to photosynthesis acclimation (loss of response to elevated $\mathrm{CO}_{2}$ ), a widely known phenomenon that usually occurs when plants are subjected to elevated atmospheric $\mathrm{CO}_{2}$ and might affect productivity estimation in DGVMs. Despite this, current models have improved substantially, compared to earlier models which had a rudimentary and very simple representation of vegetation-atmosphere interactions. In this paper, we describe this evolution through generations of models and the main events that contributed to their improvements until the current state-of-the-art class of models. Also, we describe some main challenges for further improvements to DGVMs.

Keywords Global changes $\cdot$ DGVMs $\cdot$ Maximum velocity of carboxylation $\cdot$ Acclimation

\section{Introduction}

The first terrestrial system designs were made by Alexander Humboldt, in 1849 and August Grisebach in 1872, which sought to associate climate and vegetation. In 1884 , Wladimir Koppen produced a classification system of vegetation, temperature, and precipitation that was the start of predictive modeling for plant geography (Fisher et al. 2014). In the twentieth century, the late 1960s, the atmospheric global circulation models (ACGMs) used for simulating the interaction between the atmosphere and the land surface did not take into account vegetation as a key component. When vegetation 
models emerged, they incorporated the mathematical representation of photosynthesis developed in the early 1980s (Farquhar et al. 1980) (FvCB). The concept of dynamic global vegetation models (DGVMs) was developed at the International Institute for Applied Systems Analysis (IIASA) during 1988-1990. DGVMs combined four areas of research in a single framework: plant geography, plant physiology and biogeochemistry, vegetation dynamics, and biophysics (Prentice et al. 2007). One basic requirement for a dynamic vegetation model is that it must simulate plant growth, mortality, and competition (Arora and Boer 2006; Prentice et al. 2007).

When coupled with AGCMs, vegetation models should have the capacity to link plant physiology with ecosystem processes and provide a higher resolution than classifying vegetation by biomes alone, when a sufficient number of PFTs is used (Rogers 2014). DGVMs have the potential to exploit computing resources and processing speed to simulate vegetation responses under different climate change scenarios.

Specialists discussed the weak points in DGVMs in relation to plant physiology representation (New Phytologist Workshop, Montauk, New York, USA, April 2014, Rogers et al. 2014). Some points raised in the discussion were as follows: (1) Parameterization - model parameters are obtained by fitting equations to gas exchange data; if these parameters are then used with different equations without consideration of the assumptions underlying the original data, photosynthesis will be incorrectly estimated; (2) Photosynthesis acclimation to temperature; (3) Maximum velocity of carboxylation $\left(\mathrm{Vc}_{\max }\right)$ is estimated at a canopy level and not leaf level; therefore, a discrepancy would be underestimated in the models. These issues are appointed as weakness in the models.

In this paper, we discuss some aspects of plant physiology in vegetation models, such as maximum velocity of carboxylation $\left(\mathrm{Vc}_{\max }\right)$ and its relationship with acclimation to temperature and elevated $\mathrm{CO}_{2}$. Others aspects such as stomatal modeling, fire, phenology, carbon distribution (allocation), carbon loss (senescence, exudation, fructification), and competition between species and air pollution (i.e., interactions between trace gases - except $\mathrm{CO}_{2}$, climate change, and vegetation) (Arneth et al. 2012) were not included in this work. We also describe the evolution of vegetation-atmosphere interactions representation in ACGMs up to the actual state-of-the-art DGVMs.

\section{Evolution of the models}

\section{AGCMs}

The AGCMs that were developed in the late 1960s were created for the purpose of estimating the atmospheric global circulation and exchange of latent and sensible heat between the surface and the atmosphere. Early AGCMs incorporated very simple land surface parameterizations (LSPs) (Sellers et al. 1997). The LSPs are based on some surface parameters such as albedo, aerodynamic roughness, and soil moisture along the continents. The computational performance of numerical weather prediction (NWP) models was also critical to the AGCM representation. NWPs algorithms are based on mathematical and physical principles beyond datasets, allowing higher spatial resolution and hence a greater refining of results when compared with previous AGCMs. In AGCMs, the movement of the atmosphere is defined by fluid dynamics equations incorporating the mechanical forces of gravity, the rotation of the Earth, temperature, and pressure gradients caused by friction and drag forces as the wind in the lower atmosphere (Sellers et al. 1997).

\section{First generation of vegetation models}

The first-generation vegetation models, in the early 1980s, were designed to integrate climate-surface representation, explicitly recognizing the influence of vegetation on the calculation of the surface energy balance (Dickinson et al. 1984; Sellers et al. 1986) (Fig. 1). While in the AGCMs, the vegetation was seen only as a permeable sheet between the soil and atmosphere, without any interaction, the first generation of vegetation models sought to model the soilvegetation system and how the surface interacts with the atmosphere. Basically, biophysical models considered the following interactions:

- Absorption of radiation: the spectral properties of the leaves and the multiple reflections between them (canopies are highly absorbent of photosynthetically active radiation (PAR) and moderately reflective in the infrared spectra);

- Transfer of momentum: in general, canopies have a rough and porous surface. Turbulence contributes to increased transport of latent heat and sensible heat from the surface to the atmosphere;

- Functioning of stomata: the importance of stomata for water vapor fluxes to the external environment was first considered. According to Sellers et al. (1997), the response of the stomata on the environment can be parameterized by the equation:

$g_{\mathrm{s}}=g_{\mathrm{s}}(\mathrm{PAR})\left[f\left(\delta_{\mathrm{e}}\right) f(T) f(\psi)\right]$

where: $g_{\mathrm{s}}$ is the stomatal conductance; $g_{\mathrm{s}}(\mathrm{PAR})$ is the PARregulated (unstressed) value of leaf conductance; $f\left(\delta_{\mathrm{e}}\right), f(\mathrm{~T})$ 


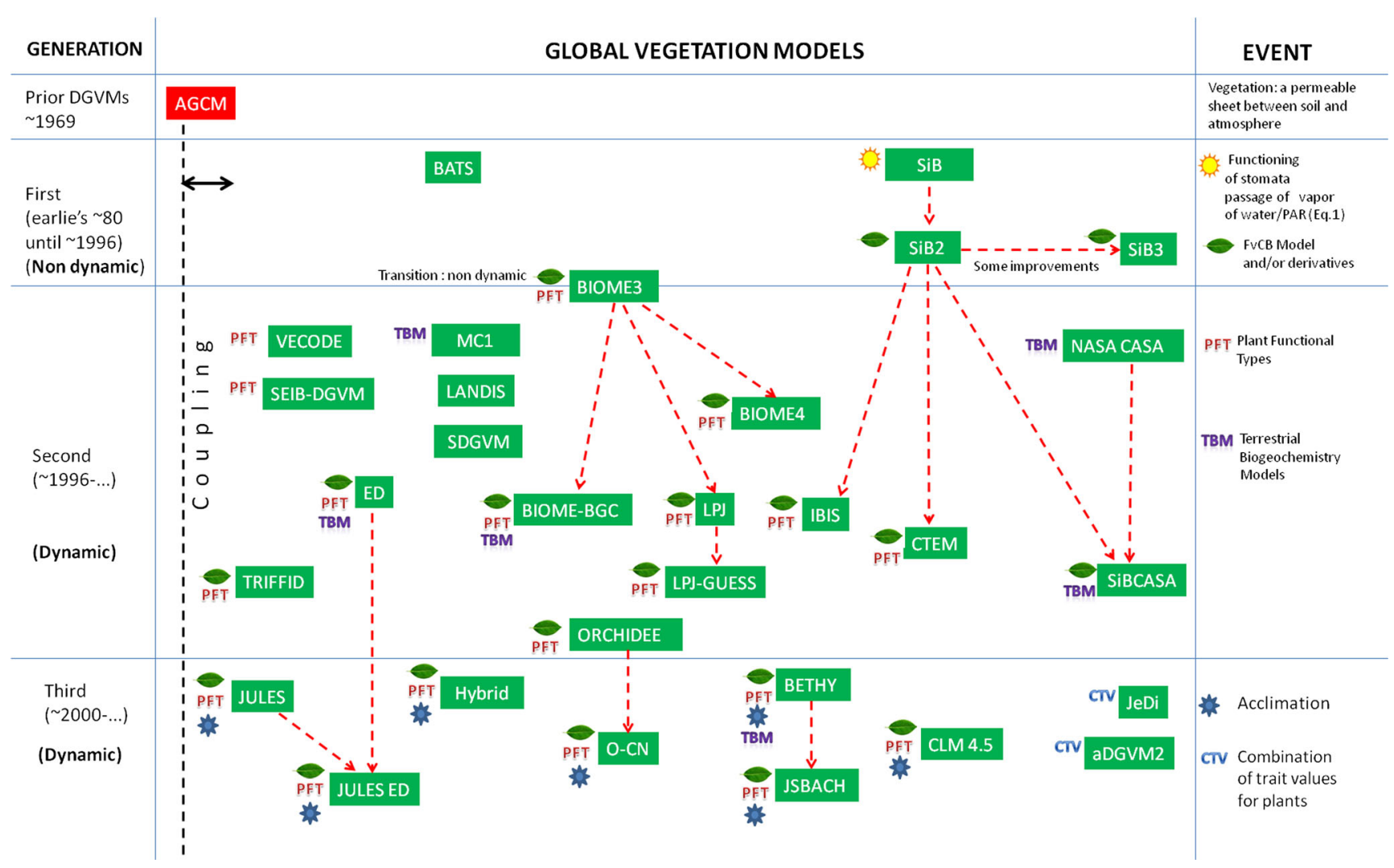

Fig. 1 Evolution of DGVMs for plant physiology processes

and $f(\psi)$ are the environmental stress factors that account for the effects of controls of vapor pressure $\left(\delta_{\mathrm{e}}\right)$, air temperature $(T)$, and leaf water potential $(\psi)$.

In the $1980 \mathrm{~s}$, there were important advances in plant physiology and biochemistry with models by Farquhar et al. (1980) (FvCB), Collatz et al. (1991), and Collatz et al. (1992) for $\mathrm{C} 4$ plants. This knowledge was incorporated in some models of this generation (Fig. 1 and Table 1).

Farquhar, von Caemmerer, and Berry $(F v C B)$ photosynthesis model

The calculation of carbon assimilation is given by gross production of photosynthesis for C3 plants and it is expressed as a minimum of three main limitations in the plant capacity to fix carbon (Farquhar et al. 1980; Farquhar and Sharkey 1982; Collatz et al. 1991). The gross photosynthesis rate per leaf area, $\mathrm{Ag}\left(\mathrm{CO}_{2} \mathrm{~mol} \mathrm{~m} \mathrm{~s}^{-2}\right)$, is given by

$A_{g} \approx \min \left(J_{e}, J_{c}, J_{s}\right)$

where $J_{\mathrm{e}}$ is the light-limited rate of photosynthesis, $J_{\mathrm{c}}$ is the Rubisco-limited rate for photosynthesis, and $J_{\mathrm{s}}$ is the triose phosphate limitation for photosynthesis. In the DGVMs, the gross primary productivity (GPP) is calculated over time for each plant functional type (i) as such:

$\mathrm{GPP}=\int A_{g, i} d t$

The net primary productivity (NPP) over time for each plant functional type is given by the sum of carbon assimilation (Eq. 4). The equation below also includes carbon loss from the respiration processes:

$\mathrm{NPP}=(1-\eta) \int\left(A_{g, i}-R_{\text {leaf }, i}-R_{\text {stem }, i}-R_{\text {root }, i}\right) d t$

where $R_{\text {leaf }, i}$ is the leaf respiration, $R_{\text {stem, } i}$ is the stem respiration, $R_{\text {root }, i}$ is the root respiration, and $\eta(\sim 0.33)$ is a fraction of carbon lost in building the structure of the plant due to respiration during growth (Foley et al. 1996).

Despite the advances in plant physiology, the firstgeneration models did not incorporate concepts of dynamic vegetation.

\section{Second generation of vegetation models}

In the second generation, models were implemented with considerations for growth, mortality, and competition of plants, 


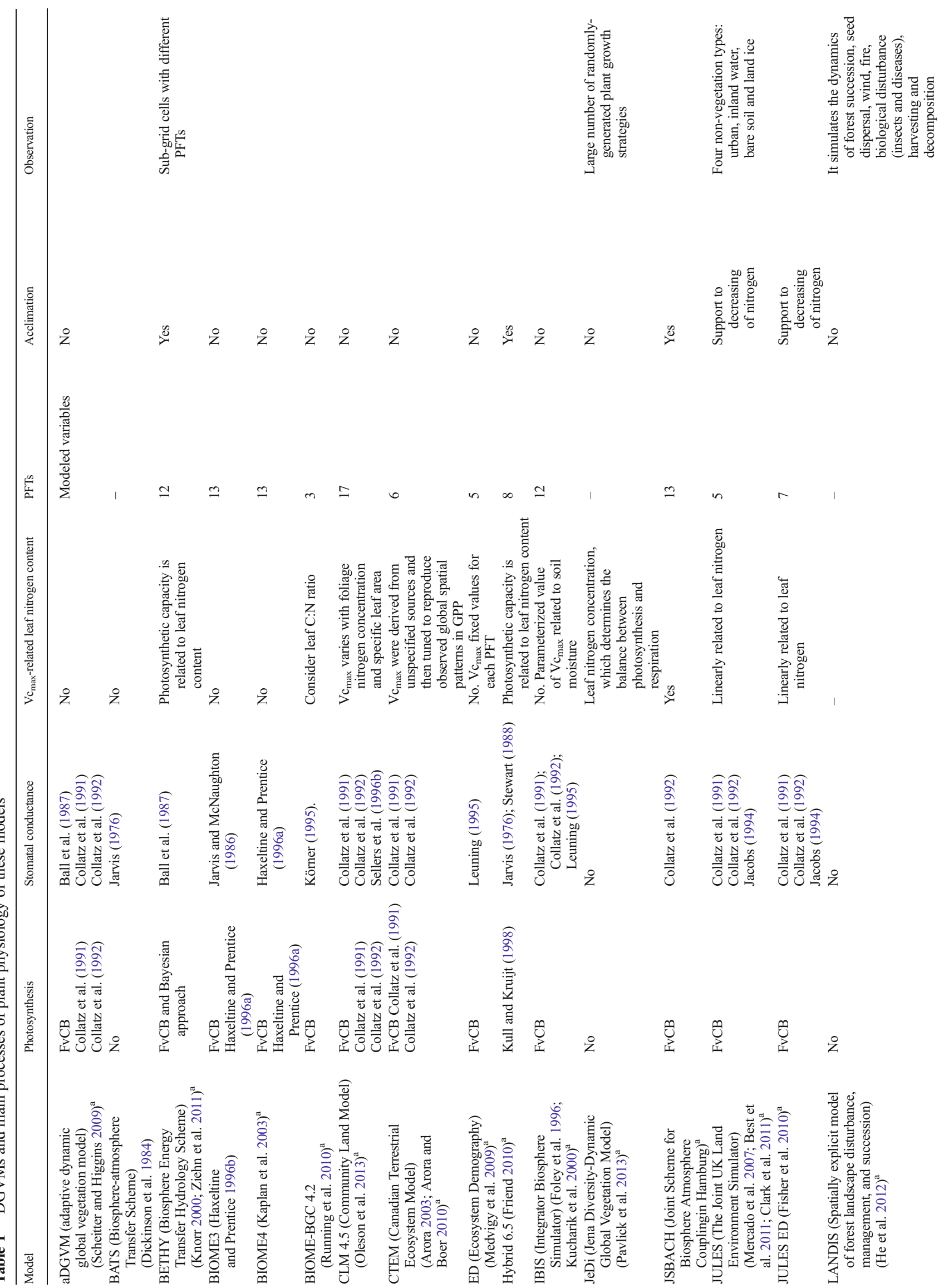




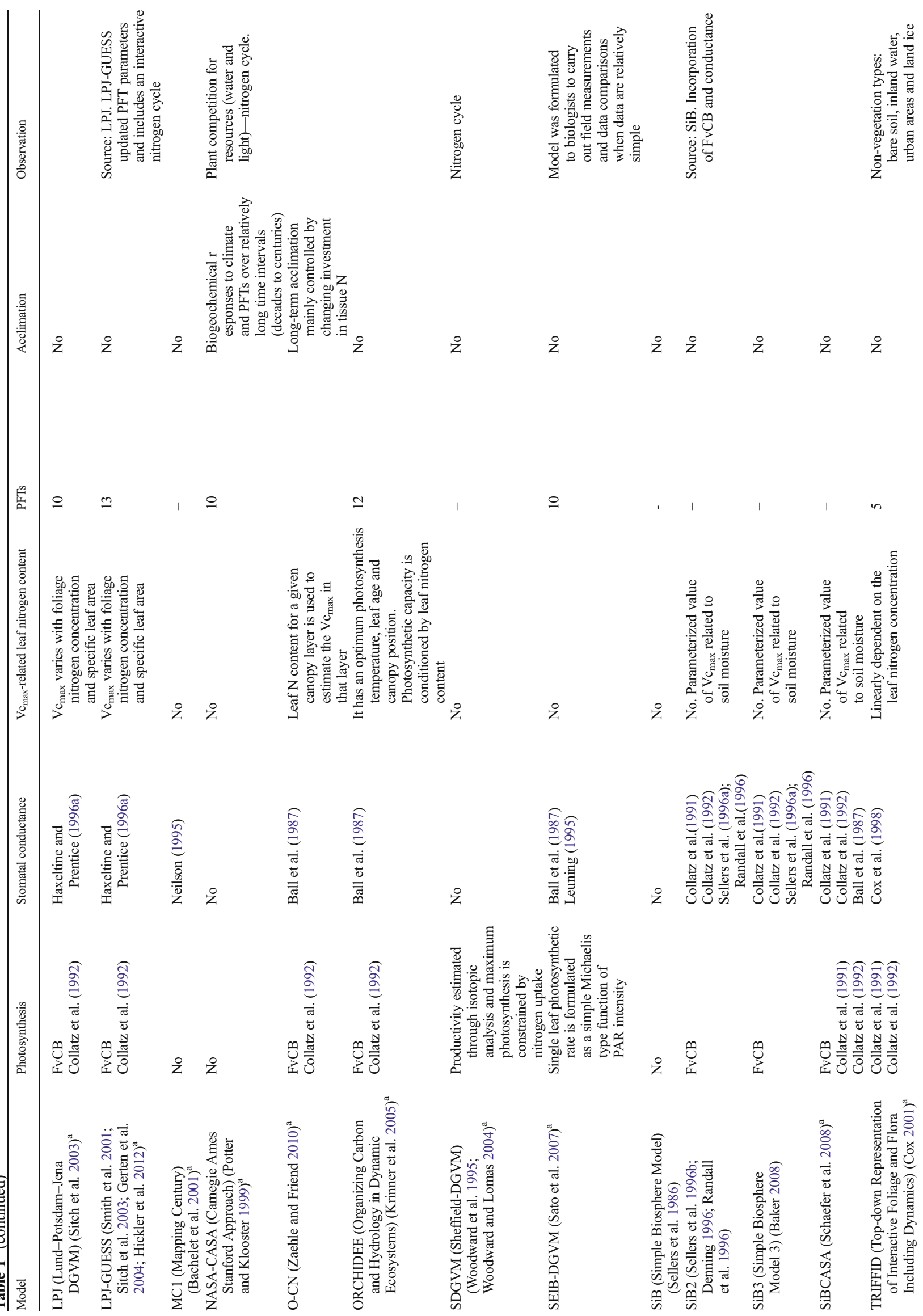


featuring the concept of dynamic vegetation (Prentice et al. 2007). Another concept introduced was that of PFTs to represent the main types of plants on the planet (Box 1981, 1996). Biome3 (Haxeltine and Prentice 1996b) is partly a secondgeneration model, because it used PFTs but not dynamic vegetation (Fig. 1). During the second-generation period, emerged the terrestrial biogeochemistry models (TBMs) that are described in "Terrestrial biogeochemistry models".

\section{Plant functional types}

The use of plant functional types (PFTs) has become an important component in DGVMs to simulate vegetation responses to environmental changes at a regional or global scale. PFTs represent the world's most important plant types, characterize them through their functional behavior, and provide complete, geographically representative coverage of the world's land areas (Box 1996). Box (1996) observed three main approaches to PFTs that have been applied in the models: (i) a physiological focus on plant's internal function, especially at the level of basic metabolism; (ii) an ecological focus on function in relation to plant form and environmental conditions; and (iii) a geophysical representation of how plant functions affect the adjacent atmosphere. Generally, DGVMs contain a number of PFTs that vary from 5 to 19 (Scheitter and Higgins 2009; Rogers 2014). However, Lavorel et al. (2007) observed that DGVM using a low number of PFTs (less than 13) might produce coarse results, simulating abrupt changes in vegetation instead of smooth gradients that are more commonly found in nature (Quillet et al. 2010). As well, Körner (1993) argued that boundaries between functional groups are often missing and discretization becomes harder.

\section{Terrestrial biogeochemistry models}

Terrestrial biogeochemistry models (TBMs) are a subset of DGVMs (e.g., BETHY, ED, MC1, NASA-CASA) that were originally developed with the main goal of simulating NPP, using simpler parameterizations than the $\mathrm{FvCB}$ model (Prentice et al. 2007). For example, MC1 (Neilson 1995) limits the representation of plant physiology with stomatal conductance parameters and a combination of rules. These rules generally seek for a solution through leaf area index (LAI), biologically consistent with evapotranspiration and the rainfall of the season (Neilson 1995). To avoid exceptions which can lead to absurd results, the model uses ecophysiological rules. For example, when air and soil are very dry, stomatal conductance is reduced to a value close to zero in the model. Another model of this generation, the Carnegie Ames Stanford Approach (NASA-CASA) (Potter and Klooster 1999) is based in the resource-ratio succession hypothesis (Tilman 1985), which applies to species that are dominant during succession, considering two main elements: (i) 
plant competition for resources (water and light) over relatively short periods (months and seasons); and (ii) the long-term pattern in the supply of resources, such as water and nutrients. Based on plant production as the primary carbon and nitrogen cycling source, the NASA-CASA model is designed to couple daily and seasonal patterns in soil nutrient mineralization and soil heterotropic respiration (Potter and Klooster 1999). The more recent TBMs use FvCB model for the calculation of photosynthesis for external variables (Prentice et al. 2007; Fisher et al. 2014), such as BETHY and JSBACH models (Knorr 2000; Ziehn et al. 2011).

\section{Third generation of DGVMs}

In the third generation, some models were merged to create new ones. Some incorporate acclimation to elevated $\mathrm{CO}_{2}$ or FvCB models, such as $\mathrm{O}-\mathrm{CN}$ and SibCASA, respectively. The main innovation was the implementation of some processes of acclimation, treated in "Challenges of DGVMs". Another innovation is the use of a novel approach to better represent plants traits (described in "Plant traits"), with the purpose of eliminating the limitation of low number of PFTs (more details on the next section).

\section{Plant traits}

Despite the fact that DGVMs allowed vegetation ecologists and meteorologists to address important questions in Earth System Sciences, the PFT approach still poses limitations in the representation of competition and responses of plant traits to environmental conditions. Plant traits can be related to plant function in relation to main environmental constraints, and these same traits are relevant to the distribution of species along gradients of climate, nutrient availability, and disturbance (Lavorel et al. 2007). Most DGVMs simulate plant functional responses that are based on observed correlations among their morphological, physiological, biochemical, reproductive, or demographic characteristics. However, this approach is not sufficient to predict changes in ecosystem processes directly from projected changes in plant species composition in response to global change (Lavorel et al. 2007; Pavlick et al. 2013; Fisher et al. 2014). A more realistic approach is important, in order to associate functional groups (species with a similar effect on one or several ecosystem functions, primary productivity, nutrient cycling) with groups of species with a similar response to a particular environmental factor; e.g., resource availability, disturbance, or $\mathrm{CO}_{2}$ concentrations. Some models such as JeDi DGVM (Pavlick et al. 2013) and aDGVM or aDGVM2 (Scheitter and Higgins 2009, 2013) emerged after with this purpose. Both models use computational algorithms and use a combination of traits of plants that allow multiple possibilities to characterize plant communities, growth, and competition (Fig. 1 and Table 1). JeDi, for example, generates a large number of hypothetical plant growth strategies, each defined by 15 functional trait parameters that characterize plant behavior with regard to carbon allocation, phenology, and ecophysiology. The trait parameter values are randomly sampled from their full observed or theoretical ranges. The plant growth module simulates the development of the plant growth strategies based on fundamental ecophysiological processes (e.g., photosynthesis, respiration, allocation, phenology, and turnover). The environmental conditions of each strategy are provided by the land surface module, which simulates canopy, interception, evaporation, root water uptake, and runoff using daily meteorological forcing as shortwave and longwave radiation, air temperature, and precipitation (Pavlick et al. 2013).

\section{Challenges of DGVMs}

The greater uncertainties of DGVMs has its origin in the physiological processes (Huntingford et al. 2013; Fisher et al. 2014; Walker et al. 2015; Belinda et al. 2015; Lin et al. 2015). We discuss some of these physiological processes below.

\section{Acclimation to temperature and $\mathrm{CO}_{2}$}

A challenging issue for models is to represent plant acclimation. The responses of plants to increasing temperature and $\mathrm{CO}_{2}$ concentration in the atmosphere are still poorly understood at scales relevant for models (Smith and Dukes 2012; Belinda et al. 2015). However, most DGVMs assume that plant respiration $\left(\mathrm{CO}_{2}\right.$ release) increases exponentially with temperature, regardless of acclimation (Atkins et al. 2008; Smith and Dukes 2012). The use of static parameters causes DGVMs to respond without adjusting to environmental changes (Belinda et al. 2015). Smith and Dukes (2012) surveyed 17 DGVMs under three points of view of processes of acclimation: (1) photosynthesis in relation to temperature, (2) autotrophic respiration in relation to temperature, and (3) photosynthesis in relation to elevated $\mathrm{CO}_{2}$. Some models incorporate acclimation to some extent in their simulations (Belinda et al. 2015), but none of these analyzed by Smith and Dukes (2012) contemplates the three main aspects of acclimation cited above.

Acclimation to temperature and $\mathrm{CO}_{2}$ concentration occurs in many species of different functional groups (Tjoelker et al. 1999). Temperature acclimation can occur in a few days and it results from an adjustment of metabolism of respiration to compensate for changes in temperature (Atkin and Tjoelker 2003). There are many uncertainties concerning temperature acclimation. Many plants adjust the temperature sensitivity of photosynthesis to the temperatures they experience in the preceding days and weeks (Rogers et al. 2014; Way and Yamori 
2014). However, few DGVMs include this process of acclimation (Smith and Dukes 2012; Rogers et al. 2014).

In relation to $\mathrm{CO}_{2}$, direct effects occur because rising $\mathrm{CO}_{2}$ increases the activity of Rubisco and the inhibition of RuBP oxygenation, reduction of stomatal aperture affecting mitochondrial respiration and others (Sage 2002). Because of these direct effects, the carbon and water balance in plants is altered leading to secondary effects on growth, resource partitioning, and defense compounds synthesis. According to Sage (2002), the photosynthetic stimulation that initially follows an exposure to elevated $\mathrm{CO}_{2}$ generally leads to a significant enhancement of leaf carbohydrate levels and a burst of growth. However, with a few days to weeks of exposure to $\mathrm{CO}_{2}$ in high levels, leaf protein levels may begin to decline, decreasing Rubisco content and consequently the photosynthetic capacity and thus reducing growth enhancement. Also, positive responses of photosynthesis to elevated $\mathrm{CO}_{2}$ concentrations may decrease over time in longer term studies due to limitation by nutrients (nitrogen uptake) needed to sustain the shortterm response, a phenomenon known as progressive nutrient limitation (PNL) (Norby and Zak 2011; Smith and Dukes 2012; Rogers et al. 2014; Belinda et al. 2015).

DGVMs must reproduce these primary and secondary effects. Despite uncertainties observed in the models, physiologists that were present in the Montauk, New York, meeting suggested that the representation of $\mathrm{CO}_{2}$ acclimation in the O$\mathrm{CN}$ model is quite close to their understanding of this process (Rogers et al. 2014).

According to Berry et al. (2010) climate simulations are sensitive to small changes in stomatal conductance. However, still it is not known whether all plants in the terrestrial biosphere are responding to the $\mathrm{CO}_{2}$ concentration growing by decreasing conductance, as represented in the simulations (Leakey et al. 2009; Berry et al. 2010). Under conditions of high atmospheric $\mathrm{CO}_{2}$ concentrations, a decrease in stomata density in plants was observed (Beerling and Royer 2002). Long-term and paleoecological studies with plant material showed an inverse relationship between the variations of $\mathrm{CO}_{2}$ and the number of stomata, that is, the higher the concentration of $\mathrm{CO}_{2}$ in the atmosphere, the lower the stomata density (Beerling and Royer 2002). Berry et al. (2010) raised the question: are the DGVM simulations adequate representations of how stomata are responding to global changes?

Studies of stomata functioning are also considered a difficult and challenging area (Berry et al. 2010). Berry and colleagues commented that experiments with Free Air $\mathrm{CO}_{2}$ Enrichment (FACE) (Ainsworth and Long 2005), using elevated atmospheric $\mathrm{CO}_{2}$, has showed a decrease of stomatal conductance. Guard cells control the exchange of gases from inside the leaf and the atmosphere, they also acclimate to atmospheric concentrations of $\mathrm{CO}_{2}$ (Hetherington and Woodward 2003). In the Montauk, New York, meeting, some specialists showed the importance of incorporating genetic variation in stomatal sensitivity to photosynthesis, relative humidity, and $\mathrm{CO}_{2}$ into model parameterizations (Rogers et al. 2014).

Another issue is the estimation of $\mathrm{Vc}_{\max }$ when acclimation occurs. Generally, a reduction of the $\mathrm{Vc}_{\max }$ rate is observed in plants growing in elevated $\mathrm{CO}_{2}$ in FACE experiments (Long et al. 2004; Ainsworth and Rogers 2007). This reduction varies with PFT. Legumes and trees showed a reduction of 8 and $6 \%$, respectively; otherwise, shrubs and grass had a reduction of 18 and $16 \%$, respectively (Ainsworth and Long 2005; Ainsworth and Rogers 2007). A challenge for the refinement of $\mathrm{Vc}_{\max }$ estimation in DGVMs would be to represent this reduction of $\mathrm{Vc}_{\max }$ rate for each PFT. A further issue is how to implement nutrient limitation (nitrogen and phosphorus) in photosynthesis within the models. Generally, DGVMs adopt an approach in the estimation of $\mathrm{Vc}_{\max }$ considering a relationship between $\mathrm{Vc}_{\max }$ and leaf $\mathrm{N}$ content (Kattge 2009; Smith and Dukes 2012; Rogers 2014). Carbon assimilation may be limited by nitrogen leaf content (Kattge 2009; Walker et al. 2015) (Fig. 2). However, models do not yet represent the decline of carbon assimilation due to progressive nitrogen limitation (PNL) observed in plants grown in a
Fig. 2 Classification of DGVMs as to $\mathrm{FvCB}$ model and $\mathrm{Vc}_{\max }$ related to the nitrogen content in the leaf

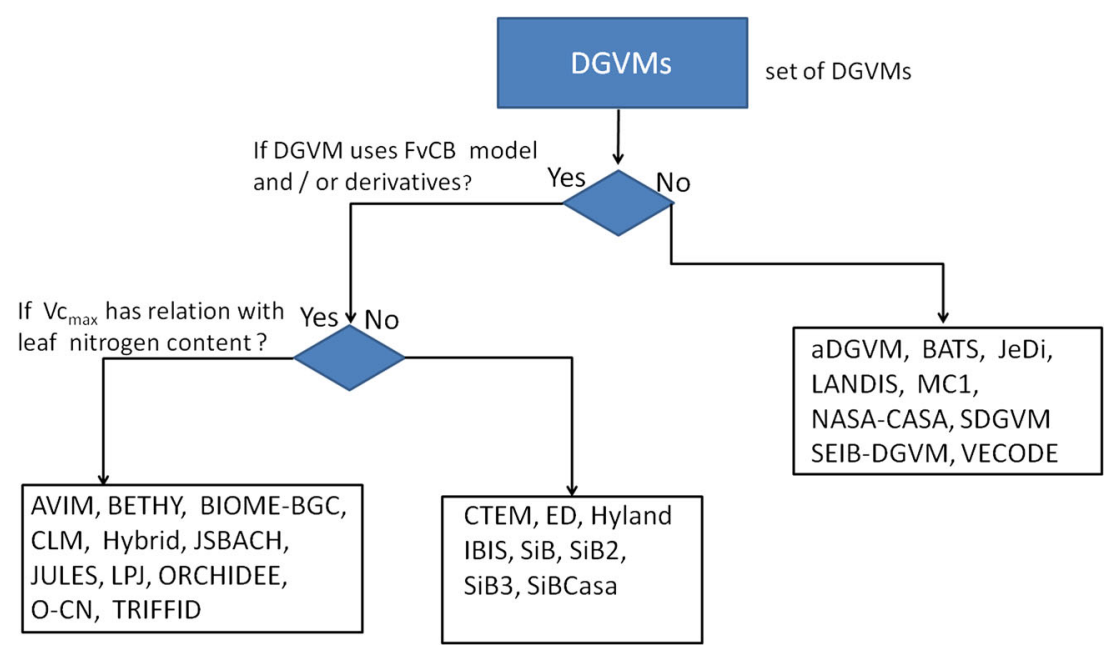


atmosphere with elevated $\mathrm{CO}_{2}$, such as in the FACE experiments (Leakey et al. 2009; Smith and Dukes 2012; Fisher et al. 2014; Walker et al. 2015).

\section{Maximum velocity of carboxylation}

Maximum velocity of carboxylation $\left(\mathrm{Vc}_{\max }\right)$ is considered one of the most critical parameters for modeling vegetation in face of global changes (LeBauer et al. 2013; Rogers 2014; Dietze 2014) and has a direct impact on gross primary productivity (GPP) (Bonan et al. 2012; LeBauer et al. 2013; Rogers 2014; Dietze 2014). In the calculation of GPP, several environmental parameters are needed: light, temperature, atmospheric $\mathrm{CO}_{2}$, nitrogen, and water (McGuire et al. 1992; Fisher et al. 2014). Because of the critical dependency on empirical parameters and because those parameters are not well characterized globally over space and time, DGVMs that rely on carbon assimilation approaches may suffer from large uncertainties associated to these parameters (Arora 2002; Fisher et al. 2014).

Another uncertainty observed in simulations of DGVMs is that they tend to underestimate GPP (Bonan et al. 2011; 2012; Dietze 2014). This can be attributed to the lack of data used for proper $\mathrm{Vc}_{\max }$ calibration and the fact that canopy-level $\mathrm{Vc}_{\max }$ values are used, which are lower than those observed at the leaf level (Schaefer et al. 2012; Bonan et al. 2012; Dietze 2014). This difference is in the measurement of canopy-level nitrogen that is more imprecise than leaf-level nitrogen content measurement (Schaefer et al. 2012). Bonan et al. (2011) show the need to properly represent nitrogen effects on $\mathrm{Vc}_{\max }$ when they compare output of $\mathrm{Vc}_{\text {max }}$ from models versus global values of $\mathrm{Vc}_{\max }$ compiled by Katge et al. (2009). Using a nitrogen function to estimate $\mathrm{Vc}_{\max }$ gives more accurate results (Bonan et al. 2011). Another methodology for $\mathrm{Vc}_{\max }$ estimation is to derive parameter values from canopy scale eddy covariance flux measurements (Misson et al. 2006; Santarem et al. 2007; Ziehn et al. 2011; Bonan et al. 2012). Using high-frequency eddy covariance flux measurements, net exchange ecosystem (NEE), latent heat, sensible heat, and net radiation, Santarem et al. (2007) demonstrated skill in estimating carboxilation rates $\left(\mathrm{Vc}_{\max }\right)$. However, this approach explicitly recognizes the difficulty in applying parameter values obtained at the leaf-level to larger scales (Bonan et al. 2012). Yet another issue, Rogers (2014) noted a wide variation in $\mathrm{Vc}_{\max }$ used in models that had identical PFTs and which sought to represent the $\mathrm{CO}_{2}$ uptake of the same biomes, which is critical due to the role of $\mathrm{Vc}_{\max }$ in the carbon cycle.

The task of estimating GPP of a biome is not trivial. Calculations for monocultures are relatively easier in comparison with natural biomes which show enormous variety of life forms or PFTs (Bonan et al. 2002). When $\mathrm{Vc}_{\max }$ is not well calibrated, errors and uncertainties can be added to productivity calculation.

\section{Final remarks}

Physiological processes play a critical role in DGVMs, and additional field data for $\mathrm{Vc}_{\max }$ calibration is of particular interest. Acclimation to temperature and $\mathrm{CO}_{2}$ is an emerging issue as a strategy to improve DGVMs. However, there is an unrealistic representation of acclimation in most of the models. Taking into account an atmosphere with elevated $\mathrm{CO}_{2}$ concentrations, the nutrient limitation in photosynthesis and reduction of $\mathrm{Vc}_{\max }$ rate are not well represented in DGVMs, which in our opinion are great challenges for improving the models. Furthermore, current DGVMs continue to incorporate new knowledge from experimental studies on the ecophysiological responses to environmental changes and observations from the functional structure of plants. Models are important tools that can help understand the relations in the Earth system, as well as to support policy decisions, by drawing different climatic scenarios of the planet's future.

\section{References}

Ainsworth E, Long S (2005) What have we learned from 15 years of freeair $\mathrm{CO}_{2}$ enrichment (FACE)? A meta-analytic review of the responses of photosynthesis, canopy properties and plant production to rising $\mathrm{CO}_{2}$. New Phytol 165:351-372

Ainsworth E, Rogers A (2007) The response of photosynthesis and stomatal conductance to rising $\left[\mathrm{CO}_{2}\right]$ : mechanisms and environmental interactions. Plant Cell Environ 30:258-270. doi:10.1111/j.13653040.2007.01641.x

Arneth A et al (2012) Future challenges of representing land-processes in studies on land-atmosphere interactions. Biogeosciences 9:35873599. doi:10.5194/bg-9-3587-2012

Arora VK (2002) Modeling vegetation as a dynamic component in soilvegetation-atmosphere transfer schemes and hydrological models. Rev Geophys 40:3-1-3-26

Arora VK (2003) Simulating energy and carbon fluxes over winter wheat using coupled land surface and terrestrial ecosystem models. Agric For Meteorol 118:21-47

Arora VK, Boer GJ (2006) Simulating competition and coexistence between plant functional types in a dynamic vegetation model. Earth Interact 10(10): 1

Arora VK, Boer GJ (2010) Uncertainties in the 20th century carbon budget associated with land use change. Glob Chang Biol16: 3327-3348.CTEM - Available: http://www.cccma.ec.gc.ca/ctem/ competition/ Accessed in Dec 272014

Atkin OK and Tjoelker MG (2003) Thermal acclimation and the dynamic response of plant respiration to temperature. TRENDS Plant Sci 8 no. 7

Atkin OK et al (2008) Using temperature-dependent changes in leaf scaling relationships to quantitatively account for thermal acclimation of respiration in a coupled global climate-vegetation model. Glob Chang Biol 14:2709-2726. doi:10.1111/j.1365-2486.2008.01664.x

Bachelet D et al. (2001) MC1: A dynamic vegetation model for estimating the distribution of vegetation and associated ecosystem fluxes of carbon, nutrients, and water technical documentation. Version 1.0.United States Department of Agriculture Forest Service Pacific Northwest Research Station General Technical Report PNW-GTR508 June 2001 
Baker IT (2008) Seasonal drought stress in the Amazon: reconciling models and observations. J Geophys Res 113:G00B01. doi:10. 1029/2007JG000644

Ball JT (1987) A model predicting stomatal conductance and its to the control of photosynthesis under different environmental conditions. In: Biggins I (ed) Progress in photosynthesis. Martinus Nijhoff Publishers, the Netherlands, pp 221-224

Beerling DJ, Royer DL (2002) Fossil plants as indicators of the phanerozoic global carbon Cycle. Annu Rev Earth Planet Sci 30:527-556

Belinda EM et al. (2015) Using ecosystem experiments to improve vegetation models. Nat Clim Change 5. doi: 10.1038

Berry JA et al (2010) Stomata: key players in the earth system, past and present. Plant Biol. doi:10.1016/j.pbi.2010.04.013

Best MJ et al (2011) The Joint UK Land Environment Simulator (JULES), modeldescription-part 1: energy and water fluxes. Geosci Model Dev 4:677-699. doi:10.5194/gmd-4-677-2011

Bonan GB et al (2002) Landscapes as patches of plant functional types: an integrating concept for climate and ecosystem models. Glob Biogeochem Cycles 16(2):1021. doi:10.1029/2000GB001360

Bonan GB et al (2011) Improving canopyprocesses in the Community Land Model version 4(CLM4) using global flux fields empirically inferred from FLUXNET data. J Geophys Res 116:G02014. doi:10. 1029/2010JG001593

Bonan GB et al (2012) Reconciling leaf physiological traits and canopy flux data use of the TRY and FLUXNET databases in the Community Land Model version 4. J Geophys Res 117(25C):119. doi:10.1029/2011JG001913

Box EO (1981) Macroclimate and Plant fornzs: Aii introduction to predictive modeling in phytogeography. Tasks Veget Sci. vol. 1. Junk. The Hague

Box EO (1996) Plant functional types and climate at the global scale. J Veg Sci 7:309-320

Brovkin Vet al (1997) A continuous climate-vegetation classification for use in climate-biosphere studies. Ecol Model 101:251-261

Clark DB et al (2011) The Joint UK Land Environment Simulator (JULES), model description - part 2: carbon fluxes and vegetation dynamics. Geosci Mod Dev 4:701-722. doi:10.5194/gmd-4-701201

Collatz GJ et al (1991) Physiological and environmental regulation of stomatal conductance, photosynthesis and transpiration: a model that includes a laminar boundary layer. Agric For Meteorol 54: $107-136$

Collatz GJ et al (1992) Coupled photosynthesis-stomatal conductance model for leaves of C4 plants. Aust J Plant Physiol 19:519-538

Cox PM (2001) Description of the "TRIFFID" dynamic global vegetation model. Hadley Centre Technical Note 24

Cox PM et al (1998) A canopy conductance and photosynthesis model for use in a GCM land surface scheme. J Hydrol 212-213(1998):79-94

Denning AS (1996) Simulations of terrestrial carbon metabolism and atmospheric $\mathrm{CO}_{2}$ in a general circulation model. Part 1: surface carbon fluxes. Tellus Ser B 48:521-542

Dickinson RE (1984) Modeling evapotranspiration for ThreeDimensional Global Climate models, in Hansen JE and Takahashi, Climate processes and climate sensitivity: Geophysical Monograph, 29. American Geophysical Union, 58

Dietze MC (2014) Gaps in knowledge and data driving uncertainty in models of photosynthesis. Photosynth Res 119:3-14. doi:10.1007/ s11120-013-9836-Z

Farquhar GD, Sharkey TD (1982) Stomatal conductance and photosynthesis. Ann Rev Plant Physiol 33:317-345

Farquhar GD et al (1980) A biochemical model of phtosynthetic $\mathrm{CO}_{2}$ assimilation in leaves of $\mathrm{C} 3$ species. Planta 149:78-90

Fisher R et al (2010) Assessing uncertainties in a second-generation dynamic vegetation model caused by ecological scale limitations. New Phytol 187:666-681. doi:10.1111/j.1469-8137.2010.03340.x
Fisher JB et al (2014) Modeling the terrestrial biosphere. Annu Rev Environ Resour 39:15.1-15.33

Foley JA et al (1996) An integrated biosphere model of land surface processes, terrestrial carbon balance, and vegetation dynamics. Glob Biogeochem Cycles 10(4):603-628

Friend AD (2010) Terrestrial plant production and climate change. J Exp Bot 61(5):1293-1309. doi:10.1093/jxb/erq019

Gerten D et al (2004) Terrestrial vegetation and water balance-hydrological evaluation of a dynamic global vegetation model. J Hydrol 286:249-270

Haxeltine A and Prentice IC (1996a) A general model for the Light-use efficiency of primary production. Funct Ecol, 10, (5)

Haxeltine A, Prentice IC (1996b) BIOME3: an equilibrium terrestrial biosphere model based on ecophysiologicalconstraints, resource availability, and competition among plant functional types. Glob Biogeochem Cycles 10:693-709

He HS et al. (2012) A spatially explicit model of forest landscape disturbance, management, and succession LANDIS PRO 7.0 USERS GUIDE. Available: http://landis.missouri.edu/files/LANDIS_PRO_ 70 UserGuide.pdf

Hetherington AM, Woodward FI (2003) The role of stomata in sensing and driving environmental change. Nature 424

Hickler T et al (2012) Projecting the future distribution of European potential natural vegetation zones with a generalized, tree speciesbased dynamic vegetation model. Glob Ecol Biogeograp 21:50-63

Huntingford C et al (2013) Simulated resilience of tropical rainforests to $\mathrm{CO}_{2}$-induced climate change. Nat Geosci Lett. doi:10.1038/ NGEO1741

Jacobs CMJ (1994) Direct impact of atmopsheric $\mathrm{CO}_{2}$ enrichment on regional transpiration, $\mathrm{Ph} . \mathrm{D}$. thesis, Wageningen Agricultural University

Jarvis PG (1976) The interpretation of the variations in leaf water potential and stomatal conductance found in canopies in the field. Philos Trans Royal Soc London Ser B 273:593-610

Jarvis PG, McNaughton KG (1986) Stomatal control of transpiration: scaling up from leaf to region. Adv Ecol Res 15:1-49

Kaplan JO et al (2003) Climate change and Arctic ecosystems: 2. modeling, paleodata-model comparisons, and future projections. J Geophys Res 108: D19, 8171, doi:10.1029/2002JD002559

Kattge J (2009) Quantifying photosynthetic capacity and its relationship to leaf nitrogen content for global-scale terrestrial biosphere models. Glob Chang Biol 15:976-991. doi:10.1111/j.1365-2486.2008. 01744.x

Knorr W (2000) Annual and interannual $\mathrm{CO}_{2}$ exchanges of the terrestrial biosphere: process-based simulations and uncertainties. Glob Ecol Biogeogr 9(3):225-252

Körner C (1993) Scaling from species to vegetation: the usefulness of functional groups. In: Schulze E-D, Mooney H (eds) Biodiversity and ecosystem function. Springer Ecol Studies 99, Berlin, pp 117140

Körner C (1995) Leaf diffusive conductances in the major vegetation types of hte globe. In: Schulze ED, Caldwell MM (eds) Ecophysiology of photosynthesis. Springer, New York, pp 463-490

Krinner $\mathrm{G}$ et al (2005) A dynamic global vegetation model for studies of the coupled atmosphere-biosphere system. Glob Biogeochem Cycles 19:GB1015. doi:10.1029/2003GB002199

Kucharik C et al (2000) Testing the performance of a dynamic global ecosystem model: water balance, carbon balance, and vegetation structure. Glob Biogeochem Cycles 14(3):795-825

Kull O, Kruijt B (1998) Leaf photosynthetic light response: a mechanistic model for scaling photosynthesis to leaves and canopies. Funct Ecol 12:767-777

Lavorel S (2007) Plant functional types: are we getting any closer to the holy grail? In: Canadell J, Pataki D, Pitelka L (eds) Terrestrial ecosystems in a changing world. Springer, Berlin Heidelberg 
Leakey $\mathrm{ADB}$ et al (2009) Elevated $\mathrm{CO}_{2}$ effects on plant carbon, nitrogen, and water relations: six important lessons from FACE. J Exp Bot 60(10):2859-2876. doi:10.1093/jxb/erp096

LeBauer DS et al (2013) Facilitating feedbacks between field measurements and ecosystem models. Ecol Monogr 83(2):133-154

Leuning R (1995) A critical appraisal of a combined stomatalphotosynthesis model for $\mathrm{C}_{3}$ plants. Plant Cell Environ 18:339-355

Lin YS et al (2015) Optimal stomatal behaviour around the world. Nat Clim Chang. doi:10.1038/NCLIMATE2550

Long PL et al (2004) Rising atmospheric carbon dioxide: plants FACE the future. Annu Rev Plant Biol 55:591-628. doi:10.1146/annurev. arplant.55.031903.141610

McGuire AD, Melillo JM, Joyce LA, Kicklighter DW, Grace AL et al (1992) Interactions between carbon and nitrogen dynamics in estimating net primary productivity for potential vegetation in North America. Glob Biogeochem Cycles 6:101-124

Medvigy D et al. (2009) Mechanistic scaling of ecosystem function and dynamics in space and time: ecosystem demography model version 2. J Geophys Res Biogeosci (2005-2012) 114 (G1)

Mercado LM et al (2007) Improving the representation of radiation interception and photosynthesis for climate model applications. Tellus B 59:553-565

Misson L et al (2006) Seasonality of photosynthetic parameters in a multi-specific and vertically complex forest ecosystem in the Sierra Nevada of California. Tree Physiol 26:729-741

Neilson RP (1995) A model for predicting continental scale vegetation distribution and water balance. Ecol Appl 5(2):362385

Norby JR and Zak DR (2011) Ecological lessons from free-air $\mathrm{CO}_{2}$ enrichment (FACE) experiments. Ann Rev Ecol, Evol Syst 42

Oleson KW et al. (2013) Technical description of version 4.5 of the community land model (CLM).Available in:http:/www.cesm.ucar. edu/models/cesm1.2/clm/CLM45 Tech Note.pdf. Accessed in Jan$2-2015$

Pavlick R et al (2013) The Jena diversity-dynamic global vegetation model (JeDi-DGVM): a diverse approach to representing terrestrial biogeography and biogeochemistry based on plant functional tradeoffs. Biogeosciences 10:4137-4177. doi:10.5194/bg-10-4137-2013

Potter CS, Klooster A (1999) Dynamic global vegetation modelling for prediction of plant functional types and biogenic trace gas fluxes. Glob Ecol Biogeogr 8:473-488

Prentice IC (2007) Dynamic global vegetation modeling: quantifying terrestrial ecosystem responses to large-scale environmental change. In: Canadell J, Pataki D, Pitelka L (eds) Terrestrial ecosystems in a changing world. Springer, Berlin Heidelberg

Quillet A et al. (2010) Toward dynamic global vegetation models for simulating vegetation-climate interactions and feedbacks: recent developments, limitations, and future challenges. Environ Rev

Randall DA et al (1996) A revised land surface parameterization (SiB2) for GCMs. part III: the greening of the Colorado State University General Circulation Model. J Clim 9:738-763

Rogers A (2014) The use and misuse of Vc, max in earth system models. Photosynth Res 119:15-29. doi:10.1007/s11120-0139818-1

Rogers A et al (2014) Improving representation of photosynthesis in earth system models. New Phytol 204:12-14

Running S et al. (2010) Biome BGC. Available in: http://www.ntsg.umt. edu/project/biome-bgc. Accessed in: Dec-27-2014

Sage RW (2002) How terrestrial organisms sense, signal, and respond to carbon dioxide. Integ Comp Biol 42:469-480

Santarem D et al (2007) Optimizing a process-based ecosystem model with eddy-covariance flux measurements: a pine forest in southern
France. Glob Biogeochem Cycles 21:GB2013. doi:10.1029/ 2006GB002834

Sato H et al (2007) SEIB-DGVM: a new dynamic global vegetation model using a spatially explicit individual-based approach. Ecol Model 200:279-307

Schaefer K et al (2008) Combined simple biosphere/Carnegie Ames Stanford approach terrestrial carbon cycle model. J Geophys Res 113:G03034. doi:10.1029/2007JG000603

Schaefer K et al (2012) A model-data comparison of gross primary productivity: results from the North American Carbon Program site synthesis. J Geophys Res 117:G03010. doi:10. 1029/2012JG001960

Scheiter S et al (2013) Next-generation dynamic global vegetation models: learning from community ecology. New Phytol. doi:10. 1111 nph. 12210

Scheitter S, Higgins SI (2009) Impacts of climate change on the vegetation of Africa: an adaptive dynamic vegetation modeling approach. Glob Chang Biol 15:2224-2246. doi:10.1111/j.1365

Sellers PJ and Mintz YA (1986) Simple biosphere model for use with general circulation models. J Atmosph Sci

Sellers PJ et al (1996a) A revised land surface parameterization (SiB2) for atmospheric GCMs. part I: model formulation. J Clim 9:676-705

Sellers PJ et al (1996b) Comparison of radiative and physiological effects of doubled atmospheric $\mathrm{CO}_{2}$ on climate. Science 271:1402-1405

Sellers PJ et al (1997) Modeling the exchanges of energy, water, and carbon between continents and the atmosphere. Science 275:502509

Sitch S et al (2003) Evaluation of ecosystem dynamics, plant geography and terrestrial carbon cycling in the LPJ dynamic vegetation model. Glob Chang Biol 9:161-185

Smith NG, Dukes JS (2012) Plant respiration and photosynthesis in global-scale models: incorporating acclimation to temperature and $\mathrm{CO}_{2}$. Glob Chang Biol. doi:10.1111/j.1365-2486.2012.02797.x

Smith B et al (2001) Representation of vegetation dynamics in the modelling of terrestrial ecosystems: comparing two contrasting approaches within European climate space. Glob Ecol Biogeograp 10:621-637

Stewart JB (1988) Modelling surface conductance of pine forest. Agric For Meteorol 43:19-35

Tilman D (1985) The resource-ratio hypothesis of plant succession. Am Nat 125:827-852

Tjoelker MG et al (1999) Acclimation of respiration to temperature and $\mathrm{CO}_{2}$ in seedlings of boreal tree speciesin relation to plant size and relative growth rate. Glob Change Biol 5:679-691

Walker AP. et al. (2015) Predicting long-term carbon sequestration in response to $\mathrm{CO}_{2}$ enrichment: how and why do current ecosystem models differ? doi: 10.1002/2014GB004995

Way DA, Yamori W (2014) Thermal acclimation of photosynthesis: on the importance of adjusting our definitions and accounting for thermal acclimation of respiration. Photosynth Res 119(1-2):89-100. doi:10.1007/s11120-013-9873-7

Woodward FI, Lomas MR (2004) Vegetation-dynamics -simulating responses to climate change. Biol Rev 79:643-670

Woodward FI et al (1995) A global land primary productivity and phytogeography model. Glob Biogeochem Cycles 9: 471-490

Zaehle S, Friend AD (2010) Carbon and nitrogen cycle dynamics in the O-CN land sur face model: 1. Model description, site-scale evaluation, and sensitivity to parameter estimates. Glob Biogeochem Cyc 24, GB1005. doi: 10.1029/2009GB003521

Ziehn $\mathrm{T}$ et al (2011) Improving the predictability of global $\mathrm{CO}_{2}$ assimilation rates under climate change. Geophys Res Lett 38:L10404. doi:10.1029/2011GL047182 